\title{
Exploring the interdependence between gainsharing and performance evaluation in a credit union, $* *$
}

\author{
Caroline da Silva ${ }^{1}$ \\ (D) https://orcid.org/0000-0003-3613-8071 \\ Email: carolinesilvactb@gmail.com \\ Crisiane Teixeira da Silva ${ }^{1}$ \\ (D) https://orcid.org/0000-0002-8370-6927 \\ Email: crisiane.silva26@gmail.com \\ Daniel Magalhães Mucci² \\ (D) https://orcid.org/0000-0002-0658-1470 \\ Email: danielmmucci@usp.br \\ Franciele Beck ${ }^{1}$ \\ (D) https://orcid.org/0000-0001-7390-5933 \\ Email: fbeck@furb.br
}

\begin{abstract}
${ }^{1}$ Universidade Regional de Blumenau, Programa de Pós-Graduação em Ciências Contábeis, Blumenau, SC, Brazil
${ }^{2}$ Universidade de São Paulo, Faculdade de Economia, Administração e Contabilidade, Departamento de Contabilidade e Atuária, São Paulo, SP, Brazil
\end{abstract}

Received on 05.03.2020 - Desk acceptance on 05.23.2020 - $3^{\text {rd }}$ version approved on 12.23.2020 - Ahead of print on 05.19.2021

Editor-in-Chief: Fábio Frezatti

Associate Editor: Cláudio de Araújo Wanderley

\begin{abstract}
This study aims to investigate the interdependence between gainsharing and performance evaluation (objective and subjective) in a credit union. There is a recent debate on the interdependence between management control practices, which emerges from the discussion of control packages or systems. This study delves into this discussion by investigating the complementarity between gainsharing (group incentive modality) and performance evaluation in a credit union context, given the need for qualitative empirical studies on this phenomenon. This study is considered relevant because the joint use of management control practices can allow organizations to effectively mitigate control problems such as lack of direction, motivation, and competence. This research promotes insights into management control practices' operation - given the discussion of complementarity between gainsharing, which is not a prevalent incentive system in most organizations - and objective and subjective performance evaluation. The methodology consists of a qualitative field study in a credit union using data collection, interviews, and access to documents analyzed using an interpretive approach. This research presents evidence on the phenomenon of interdependence between management control practices, adding to the literature by addressing different forms of complementarity between a group incentive system in the form of gainsharing and performance evaluation. It became evident that gainsharing reinforces the objective performance evaluation process by mitigating motivation and direction problems, while the subjective performance evaluation compensates the objective performance evaluation by shifting the focus of the evaluation to the individual's skills.
\end{abstract}

Keywords: management control practices, complementarity, gainsharing, performance evaluation, credit union.

\section{Correspondence address}

Caroline da Silva

Fundação Universidade Regional de Blumenau, Programa de Pós-Graduação em Ciências Contábeis

Rua Antônio da Veiga, 140 - CEP 89030-903

Itoupava Seca - Blumenau - Santa Catarina - Brazil

*Paper presented at the XIII Congress of Anpcont, São Paulo, SP, Brazil, June 2016.

**The authors would like to thank the Coordination for the Improvement of Higher Education Personnel (Capes) for the financial support in carrying out this research. Also, the authors thank the reviewers for the contributions received. 


\section{INTRODUCTION}

In recent years there has been a growing debate about the conceptualization and treatment of management control practices under the logic of package or systems (Grabner \& Moers, 2013; Malmi \& Brown, 2008; Merchant \& Otley, 2020). According to Grabner and Moers (2013), management control practices form a system when they are interdependent with each other. Interdependence "implies that the value of a management control practice depends on the use of another management control practice, and vice versa" (Grabner \& Moers, 2013, p. 408). Choi (2020) suggests, based on the dynamic strength model, that interdependence consists of the interaction between management control practices, in the sense that one practice influences the direction and magnitude of the benefit performed by another management control practice. Bedford (2020) ponders the magnitude of the effects of interdependence between practices and their connection within a package.

As a result of the concept of interdependence, the notion of complementarity and substitution between management control practices emerges. Complementarity defines how the benefits of using a practice increase using another one of management control (Grabner \& Moers, 2013). Bedford (2020) recently reported the existence of three ways to generate the effects of complementarity, since a management control practice: (i) compensates for the limitations of another practice (ii), reinforces the effectiveness of another practice, and (iii) enables and creates the conditions for another practice to mitigate control problems. Such problems are the lack of direction regarding objectives, the lack of motivation, and individuals' limitations (Merchant \& Van der Stede, 2014).

Supported by this discussion, Friis, Hansen, and Vámosi (2015) investigated the relationship of complementarity and substitution of management control practices from the context of changing an incentive system. According to Friis et al. (2015), there are two groups of studies that discuss this theme: the first deals with the interdependence relationship between two practices (for example, the interrelationship between the incentive system and another management control practice), and the second deals with the inter-relationship between the incentive system and a series of practices within the management control system (Friis et al., 2015). Demartini and Otley (2020), in turn, discussed the complementarity of the different control mechanisms from the dyads of management control practices, such as performance evaluation, budget, and use of non-financial measures and their effects on the effectiveness of controls and process innovation, based on the loose-coupling approach (duality between efficiency and flexibility). Other studies discuss conceptually the interdependence and complementarity of management control practices (Bedford, 2020; Choi, 2020), which shed light on aspects that can be investigated by future empirical studies (Merchant \& Otley, 2020).

Considering the need for more qualitative empirical evidence to investigate the phenomenon of interdependence, in particular complementarity and its effects on organizations (Merchant \& Otley, 2020), this paper aims to discuss the following research question: how the interdependence of practices of performance evaluation and reward system occurs in a credit union?

The investigated practices cover two of the three components that Brickley, Smith, and Zimmerman (2015) consider the organizational architecture, namely: the performance evaluation (objective and subjective) and the incentive system. Organizations adopt monitoring mechanisms such as objective and subjective performance evaluation and the system of individual and collective rewards, financial and non-financial, which aim to influence decision-making (He et al., 2020). In addition to influencing behavior, the rewards system can facilitate decisions and choices that affect the organization's performance by focusing on attention and improving knowledge.

A range of studies addresses individual perspectives and rewards. However, some authors consider several study opportunities, comparatively, focusing on group reward systems (Nyberg, Maltarich, Abdulsalam, Essman, \& Cragun, 2018; Pizzini, 2010). The system of variable financial rewards in-group is the Profit Sharing Plan (PSP) or Gainsharing (treated as synonyms in this article), which is included in this classification because it is considered a collective remuneration mechanism that links the payment for results based on measurement of group performance (Gerhart, Rynes, \& Fulmer, 2009; Nyberg et al., 2018).

The objective of this research is to investigate the interdependence between gainsharing and performance evaluation (objective and subjective) in a credit union, considering the particularities of its context. Thus, this study seeks to meet the call proposed by Merchant and Otley (2020) for conducting qualitative studies on the phenomenon of interdependence between management control practices and their implications for organizations, which occurs in this research through a study of qualitative 
case in a credit union. Therefore, this article background indicates that the interdependence between gainsharing practices and objective and subjective performance evaluation can evolve in different ways (Bedford, 2020), allowing us to understand how the complementarity between management control practices makes it more effective in mitigating problems with motivation, direction, and competence in organizations (Merchant \& Van der Stede, 2014).

Therefore, this research contributes to the management accounting literature to deepen the discussion on interdependence and, specifically, on the complementarity between management control practices. As a recent debate in the area (Bedford, 2020; Choi, 2020; Demartini \& Otley,
2020; Grabner \& Moers, 2013; Merchant \& Otley, 2020), it presents evidence about other control practices, such as gainsharing and objective and subjective performance evaluation, which previous studies do not address.

From a practical point of view, this study is part of the context of credit unions, which are guided by social and collective principles (Jovanović, Arnold, \& Voigt, 2017) and, at the same time, are institutions that belong to the banking sector, which uses mechanisms to monitor activities and assist decision-making (Jovanović et al., 2017). This study also provides insights into how management control practices work in a credit union, considering the gainsharing modality's incentive system, which is the union's leading financial incentive.

\section{THEORETICAL BACKGROUND}

\subsection{Package and System: Discussion on Management Control Practices}

The discussion about management control practices as a package is relatively recent in the management accounting literature; a topic addressed in more depth initially by Malmi and Brown (2008). As the authors characterize, the concept of a package points to a collection of practices that should not be defined as a single system (Malmi \& Brown, 2008), since they are independent practices that address unrelated control problems (Grabner \& Moers, 2013).

In particular, Grabner e Moers (2013, p. 408) argue that the package when it "represents the complete set of control practices in action, regardless of whether management control practices are interdependent and/or design choices take into account the interdependencies." Malmi and Brown (2008), from the package view, segregate the practices of the Management Control System (MCS) into five control dimensions: planning, cybernetic controls, reward and incentive system, in addition to administrative and cultural controls. To evolve this reflection, Grabner and Moers (2013) propose that management control practices can be used in an interdependent way and, therefore, suggest the idea of complementarity to understand the interdependence between management control practices.

In this sense, the authors argue that practices can be perceived as "internally consistent" systems of two types: complements and substitutes. According to Grabner and Moers (2013, p. 408), "interdependence implies that the value of a management control practice depends on the use of another management control practice and vice versa."
Complementarity is characterized when the value of practice increases with the use of another. Other empirical studies have been developed from interdependencies between management control practices (Bedford, Malmi, \& Sandelin, 2016; Demartini \& Otley, 2020; Friis et al., 2015). Friis et al. (2015) discuss implementing a new incentive system presenting complementary and substitute relationships in a manufacturing company. They argue that the complementarity of management control practices increases the efficacy of managerial control and mention the complementarity when one control mechanism increases the return of another mechanism.

Recently, Demartini and Otley (2020) pondered the relevance of defining management control practices within the package or system perspective. They advocated a more integrative look in the sense of treating this discussion not as a dualism but as a spectrum with two extremes: one uncoordinated and the other perfectly integrated, considering the theoretical approach called loose-coupling. In this context, the authors discuss the complementarity of different control mechanisms the performance evaluation, the budget, and the use of non-financial measures - considering the type and degree of their interactions. Therefore, they analyze this complementarity's impact on effectiveness and innovation (organizational constructs) (Demartini \& Otley, 2020).

Choi (2020) considers the interdependence between management control practices as the relationship between practices in which a given situation of a management control practice can change the direction and/or the intensity of the role played by another management control practice. Also, Choi (2020) addresses interdependence through the lens of dynamic 
force, according to which complementarity represents the determining force that practice of managerial control $\mathrm{D}$ can raise the magnitude of the force exerted by practice $\mathrm{C}$ and, subsequently, complementarity appears as a notion of positive cause, in which the force to be exerted by practice $\mathrm{C}$ requires the presence of practice D (Choi, 2020).

Bedford (2020) lists three elements that generate the effects of complementarity of management control practices: compensatory, reinforcing, and enabling. Compensatory effects occur when such a practice absorbs the weaknesses or barriers of another control practice. On the other hand, the reinforcement effects occur when a management control practice increases the efficacy of another control practice. Finally, the enabling effects are due to a management control practice that provides the conditions for another practice to help solve control problems (Bedford, 2020). In addition to these three, the authors highlight three causal ways to understand substitution (inhibitory, exacerbating, and instigating) and four ways about the independence between management control practices (supplementary, conflicting, redundant, and interchangeable).

This study is inserted in this discussion when analyzing the interdependence from the perspective of complementarity treated by Bedford (2020), with a focus on identifying how this element occurs in the face of the practices of the group reward system (PSP-gainsharing), of the objective performance evaluation and subjective performance evaluation. This view, regarding management control practices, reflects the context of the organization in which these practices exist and are perceived as relevant to the management process. Furthermore, the practices are aligned with the organizational architecture's two main elements (Brickley et al., 2015) that the literature has investigated in management accounting (Demartini \& Otley, 2020). In this sense, for Friis et al. (2015), there is a gap in studies that empirically discuss the complementarity between the practices mentioned.

\subsection{Gainsharing}

As one of the types of financial reward systems, the Profit Sharing Plan (PSP), or Gainsharing, is considered a mechanism that integrates performance and rewards with organizational goals and objectives, in addition to being able to encourage group actions of employees to achieve the desired performance (Gomez-Mejia, Welbourne \& Wiseman, 2000; Zondo, 2018). Thus, the emphasis on gainsharing is more focused on team goals than on individual results (Masternak \& Ross, 1992).
Among its advantages, gainsharing can be customized according to the organization's different types of objectives, such as satisfying the client and achieving financial goals (Gerhart, Rynes \& Fulmer, 2009). Also, goals tend to be objective and based on historical information, making them more transparent and more acceptable to the employee (Case, 1998). It is also worth mentioning the capacity of gainsharing to outline the culture of an organization and elevate the relationship and the transfer of knowledge (Masternak \& Ross, 1992; Arthur \& Kim, 2005), stimulating suggestions for improvement and new ideas from the employees (Arthur \& Kim, 2005).

Another relevant factor about the difference between gainsharing and other group reward systems is profit sharing based on non-financial measures (Gerhart et al., 2009; Nyberg et al., 2018). Also, gainsharing generally involves employees in drawing up plans (Arthur \& Kim, 2005) to influence their actions. As a result of this effect, group rewards encourage employees to assist in achieving objectives and monitoring among peers (Welbourne \& Gomez-Mejia, 1995).

Therefore, gainsharing tends to be defined for a short-term time environment to make the practice more adherent to the performance goals (Aguiar, Teixeira, Nossa, \& Gonzaga, 2012). Furthermore, it differs from the profit-sharing plan by the capacity to measure the group's performance or the corporate sector and the fact that the frequency of payments may be higher (Kgoedi \& Pillay, 2018).

Thus, organizations opt for group rewards, such as gainsharing, to boost the benefits of cooperation between members of a group (Nyberg et al., 2018; Pizzini, 2010). Also, Pizzini (2010) considers that group reward determinants may be linked to the interdependence between tasks, mutual monitoring of company members, and the organization's size. In this context, as an empirical contribution, Zondo (2018) points out that gainsharing becomes effective when aligned with the performance evaluation process.

Therefore, Doucouliagos, Laroche, Kruse, and Stanley (2020), when performing a meta-analysis, identified a positive effect of gainsharing on performance. However, this effect occurred more intensely in union organizations in economies in emerging countries. Thus, organizations that aim to increase employee motivation and engagement and align behaviors with organizational objectives have an alternative in implementing gainsharing to achieve this goal (Zondo, 2018). Within the control system's logic, the reward system, such as gainsharing, tends to provide more effective use of other management control practices, such as performance evaluation. 


\subsection{Performance Evaluation}

Performance evaluation aims to monitor, followup, compare, and facilitate the goals to be achieved, in addition to allowing the implementation of strategies to occur from formal and informal mechanisms (Ferreira \& Otley, 2009; Groen; Wouters, \& Wilderom, 2017; Malmi \& Brown, 2008). According to the literature, performance evaluation can be understood in two ways: objective and subjective. According to Woods (2012, p. 403), "the objective measure exists as a quantity in and of itself; in contrast, subjective measurements are based on attitudes, beliefs, and perceptions." Therefore, objective performance evaluation does not depend on the person performing it; the second (subjective) aspect involves a certain level of discretion and judgment in the evaluation process (Beuren, Von Eggert, \& Santos, 2020; Moers, 2005).

Objective performance evaluation is also known as a formal assessment, and it can focus on measuring and following-up the performance of individuals, teams, or the organization as a whole (Ittner, Larcker, \& Meyer, 2003; Moers, 2005). It is noteworthy that this evaluation is linked to the budgetary goals and/or performance indicators established in the organization, which may or may not be related to the reward system (Groen et al., 2017). In Hartmann and Slapničar (2012) view, objective performance evaluation is associated with financial metrics, based on data presented at the end of a given period in an organization.

If, on the one hand, the use of objective measures for performance evaluation allows high formalization of the process and a certain "objectivity" when removing the effect of those who perform the evaluation, on the other hand, this practice is also seen as rigid and limited (Lau \& Moser, 2008), indicating incompleteness (Bol, 2008; Bol \& Smith, 2011).

The literature has provided evidence that performance evaluation based only on these indicators may be insufficient as it does not include, for example, the characteristics and skills of employees (Bol \& Smith, 2011; Kunz; 2015). According to the literature, objective performance evaluation's limitations can even impact the organization's results due to employees' dissatisfaction regarding the effectiveness of the evaluation system (Groen et al., 2017; Jordan \& Messner, 2012).

Aiming to understand the behavioral and psychological effects involved in the evaluation and reward process in organizations, the literature in the area has advanced the discussion, mobilizing subjective performance evaluation (Bol \& Smith, 2011; Kunz, 2015; Moers, 2005). As already seen, this perspective involves the personal judgment of managers regarding subordinates, observing qualitative performance measures (Moers, 2005). In particular, Gibbs et al. (2004) highlight that subjective performance evaluation may involve: (i) the use of subjective performance measures; (ii) flexibility in the allocation of weight (ex-post) in the objective performance evaluation; and/or (iii) allowing for ex-post discretionary adjustments based on factors other than the specified ex-ante performance measure.

Financial incentives often influence the performance of an organization's employees. Thus, the combination of objective and subjective performance measures tends to facilitate the control of performance evaluation since focusing only on objective performance measures may not be the best solution for the reward. However, subjective measures can also lead evaluators to evaluation bias, mainly when these evaluations are associated with promotions in the organization.

Thus, an alternative to obtaining better results and maintain balance in the organization regarding performance evaluation is to use objective and subjective performance measures, observing the results of employees and their skills and competencies (Bol \& Smith, 2011; Jordan \& Messner, 2012).

\section{METHODOLOGICAL PROCEDURES}

The research methodology is characterized as a case study, through which it is possible to go deeper into the context, which allows investigating specific organizational environments (Ahrens \& Chapman, 2006). The research follows the interpretative approach, based on understanding meanings through people who experience the investigated phenomena (Chua, 1986; Crotty, 1998).
For selecting the case, organizations with structured management control mechanisms were observed, such as planning, performance measures, and reward system (Ferreira \& Otley, 2009). In this case, the selected union meets the requirements regarding the structure, diversity, and complexity of operations and the use of management control mechanisms (Chenhall \& Langfield-Smith, 2003). 
The procedures used for data collection were semistructured interviews and document analysis. Initially, after defining the study's object, the researchers made direct contact via telephone and e-mail with the union's administrative director to ascertain the organization's interest in conducting academic research.

The first contact enabled us to find a document in which the Corporate Governance Policy is made available, allowing us to identify principles of the guidelines that govern the study union, its administration, and control. The formalization of the research with the union studied occurred in 2018 by submitting the introduction letter and the research's ethical protocol to the administrative director. Before application, the researchers structured the interview script to understand the union's management control practices, which involved, for example: (i) union's structuring (Chenhall \& Langfield-Smith, 2003); (ii) the definition of goals/objectives (Ferreira \& Otley, 2009); (iii) the objective and subjective performance evaluation (Van Veen-Dirks, 2010); (iv) the reward system (Nyberg et al., 2018; Van Veen-Dirks, 2010); and (v) the use of performance measures (Ferreira \& Otley, 2009; Grafton, Lillis, \& Widener 2010). Table 1 presents examples of the questions for each construct.

Table 1

Sample questions to interviewees

\begin{tabular}{cl}
\hline Construct & \multicolumn{1}{c}{ Examples of Questions } \\
\hline Structure & How does a union agency structure (roles, tasks, decentralization of authority, rules, and procedures) work? \\
\hline Goals & $\begin{array}{l}\text { How does the proposition of goals occur in the union? Who is responsible for this process? What is the time horizon } \\
\text { for these goals? }\end{array}$ \\
\hline Remuneration & $\begin{array}{l}\text { The union has a job and salary plan based on the achievement of goals. What percentage of remuneration is } \\
\text { determined by the achievement of budget goals? } \\
\text { When achieving the established goals, what benefits are granted to employees? If not, is there a penalty for the group? }\end{array}$ \\
\hline $\begin{array}{c}\text { Performance } \\
\text { evaluation }\end{array}$ & $\begin{array}{l}\text { How do you determine the performance indicators by which employees will be evaluated? Do you usually follow-up } \\
\text { on whether the indicators are being achieved? If you do not reach the goals, do you seek to check with the employees } \\
\text { why the result was not achieved? What are the formal channels you use? }\end{array}$ \\
\hline
\end{tabular}

Source: Based on studies by Ferreira and Otley (2009); Grafton, Lillis and Widener (2010); Van Veen-Dirks (2010).

It is worth mentioning that, compliant to the qualitative approach, this study involved the abduction process (Dubois \& Gadde, 2002, Lukka, 2014), in which the following occurs: (i) the identification of a discussion at the theoretical level (etic) (use of performance measures and use of reward system - gainsharing); (ii) followed by identification in the field regarding the individuals' understandings (emic) about the use of these practices; and, finally, (iii) the interaction between the etic and emic perspective, reformulating or focusing the research question of the study from the deepening of the investigated phenomenon, generating new insights. In this way, the "back and forth" process between the field and theory is emphasized (Dubois \& Gadde, 2002; Timmermans \& Tavory, 2012).

The consent form for recording, the interviews' transcription, and the research ethics protocol were made available and discussed individually with each interviewee. In particular, the ethical protocol established the respondents' anonymity regarding the interviews and the possibility of recording, with the interviewee's permission. In general, it contained information about the research, the collection procedures, and the data treatment.

For access and interview people who worked in the union's day-to-day activities, seven interviews were conducted: the first six took place in 2018 and the seventh in 2020 to collect additional information. We tried to interview people who worked in the main areas of interest of the study. Thus, the administrative director, the executive director, one responsible for regional management, and four more responsible for coordinators' positions were interviewed, including two coordinators from the administrative headquarters and two from service stations. The semi-structured interviews (Table 2) were conducted by two researchers and took place on the union's premises. 
Table 2

Characterization of interviewees

\begin{tabular}{|c|c|c|c|c|}
\hline Interviewees & Category & Time in the union & Time in office & Duration time \\
\hline 1 & Director 1 & 35 years & 6 years & $1 \mathrm{~h} 30 \mathrm{~min}$. \\
\hline 2 & Director 2 & 36 years & 8 years & $56 \mathrm{~min}$. \\
\hline 3 & Manager 1 & 15 years & 7 years & $2 \mathrm{~h} 10 \mathrm{~min}$. \\
\hline 4 & Coordinator 1 & 11 years & 8 years & 1h35 min. \\
\hline 5 & Coordinator 2 & 15 years & 7 months & $1 \mathrm{~h}$ \\
\hline 6 & Coordinator 3 & 9 years & 8 years & $36 \mathrm{~min}$. \\
\hline 7 & Coordinator 4 & 3 years & 5 months & $50 \mathrm{~min}$. \\
\hline
\end{tabular}

Source: Research data (2020)

After conducting the interviews, the researchers transcribed them. The transcribed data resulted in 79 pages of records. Subsequently, the researchers read and discussed the evidence collected through the interviews and documents gathered during the field research, such as the organization chart, manuals, and reports, such as the Strategic Planning and the Performance Evaluation Primer.

\section{ANALYSIS OF RESULTS}

\subsection{Context of the Union: Structure and Mechanisms}

As noted in the interviews and internal documents made available by the union, the organization studied has a divided structure, with formally defined positions, hierarchies, and functions. Among the bodies that make up the union's governance structure, we can highlight the Union Assembly, the Board of Directors, the Fiscal Council, and the Executive Board.

The Board of Directors is made up of seven members who are responsible for electing an executive board in addition to other duties. The board consists of three members: a board coordinator, an administrative director, and an operational director. The directors coordinate the activities of thirteen managers, ten of whom are called regional managers, whose responsibility is to coordinate a group of service stations, in line with the union's strategic guidelines (a booklet that deals with competencies). The other three managers support regional managers, divided between credit management, people management, and membership organization.

Regional managers bridge the gap between the expectations set by the executive board and by the service stations' managers, designated in the union as coordinators. The coordinators act as managers of the teams that work in each service station to define the action plans (Skills Booklet). These managers are hierarchically subordinate to analysts, assistants, and interns.

The union adopts mechanisms for managing short, medium, and long-term results aligned with the perspective of the performance evaluation system (Ferreira \& Otley, 2009). It develops strategic planning every three years, from which it establishes the strategic objectives to be achieved and the strategies to be implemented. As illustrated by the Strategic Planning Booklet (20182020), the process is developed playfully for employees, contemplating twelve strategic guidelines that are broken down into tactical and operational plans, with a total of 118 purposes for fulfilling strategic planning.

In Frezatti's (2009) view, strategic planning is spread over the horizon of one year through the budget, whose function is to determine the operational and financial goals. Among the global objectives deployed in the organization, Director 2 points out the increase in the number of union members, the increase in the volume of managed resources, the increase in credit granting volume, and the identification of business opportunities with the members. From this process of defining the plan, the objectives, indicators, and goals that guide the profit-sharing plan (PSP) are established, an artifact that will be explored in the next subsection. 


\subsection{Union Incentive Systems (PSP)}

The union has been implementing a group rewards system for more than 20 years, through performance targets, referred to in the international literature as Gainsharing (Nyberg et al., 2018), or in the national one as the Profit Sharing Plan (PSP). As one of the union's priorities is the collective spirit, the PSP is for everyone, from the intern to the board (Masternak \& Ross, 1992). This attribute is illustrated by Director 2, i.e., because it is a union, "we highly value collective work, teamwork, support work between teams, and not a competition between employees."

This incentive system is designed based on performance indicators resulting from strategic planning. Based on this system, employees are rewarded twice a year, i.e., semiannually. This logic allows the board to review the performance indicators and the percentage of achievement of the respective goals, adjusting the incentives system given the internal and external circumstances.

For the PSP composition, approximately 40 performance indicators are indicated that are part of the strategic planning. From this portfolio of indicators, the executive board defines 4 to 7 performance indicators to be part of the group incentive system, such as the growth rate in the number of members, default, growth in the volume of assets, and operational efficiency index.

Also, according to documents presented to the researchers, the definition of weights, the earnings table, and the proportionality table for each indicator with the respective target are agreed by the executive board together with regional management. According to Director 2: "Then there is a greater weight for that [indicator] that needs more strength, and the weight of the one that is not reduced. Not everything goes into the PSP, only a few, the most strategic, the most important [...]"

On the other hand, in addition to the mandatory indicators, each service station is free to suggest indicators that are not in the portfolio for the next semester, making the PSP an influencer of behaviors and a facilitator in the face of improvement decisions and new ideas presented by employees at service stations (Van Veen-Dirks, 2010; Zondo, 2018). Coordinator 2 says: "For the same semester, we are unable to change the indicators, because it must have an entire historical basis, we must check if it is an opportunity to have this as an indicator [...]"

Thus, the PSP's role in the union is to intensify the desired results. Concomitantly, it aims to align and look at the employee in the face of how the result should be achieved, i.e., the vision of a PSP with purposes. Thus, according to Coordinator 4, the PSP's role: "is related to the recognition of the employee concerning the work carried out and, of course, to encourage the union's results."

Another exciting factor is that the PSP undergoes internal changes. For example, using the nomenclature "Purpose + Participation = Result," as Coordinator 4 reports: "It is still the PSP, but when we talk about the acronym internally, today its meaning for us has changed, so it remains the PSP, but we speak internally to bring that sense to the employee." Thus, the way the PSP is called within the union tends to influence the employee's behavior and purposes since the PSP will be a consequence of exercising their skills and competencies to serve the union and achieve organizational results.

In this sense, although the variable reward is collective, there are different percentages between service stations. As Director 2 reports, there are goals for each service station, directly linked to the performance indicators of each unit, from which percentages to be achieved for the PSP will be assigned. It should be noted that, as it is a group incentive system, the interviewees did not report the existence of any eligibility criteria, which is used in individual executive incentive systems.

Thus, the PSP's objective is to provide a reward for employees and not to punish them (Bonner \& Sprinkle, 2002). The punishment portrayed here does not refer to dismissals, but rather to not receiving the PSP, as Coordinator 2 reports: "the greatest penalty is not receiving this participation; wanting or not, we receive $135 \%$ of our salary there". Manager 1 states that "all service stations have the same goal, but in the control (administrative) area, for example, they have different goals," goals here translated as performance indicators.

Therefore, the PSP adopted in the investigated union is structured according to the perspective of group reward, stated by Director1: "in the union, there is no individual variable salary, everything is collective, what we call PSP." As Coordinator 2 reports: "[...] the union has a way of working that I particularly like, which is the search for results collectively, so we don't have commissions, we don't have extra, we have other types benefits, and PSP, our profit-sharing, is one of them."

In summary, according to the interviewed managers, the PSP aims to influence the teams (whether the service station or the entire union) to achieve the pre-established goals for specific indicators and, consequently, to achieve the economic and social result. Thus, it appears that the PSP can stimulate the use of performance indicators when used in a complementary way to the performance evaluation (Friis et al., 2015). 


\subsection{Objective and Subjective Performance Evaluation}

In the union, objective performance evaluation occurs at the organizational level. In this case, the performance indicators are used to evaluate all the union teams to influence the achievement of the objectives considering the variable remuneration, i.e., the PSP. This is one of the aspects that differentiate objective from subjective evaluation, in which everyone is assessed individually.

In this union, objective performance indicators are not used at the individual level, as in subjective evaluation (competency assessment). As stated by Coordinator 4, "we do not have an individual evaluation by performance or result... What we have to assess by the more objective result is our PSP, the PSP has macro indicators". Thus, objective performance evaluation aims to achieve goals based on Strategic Planning and broken down into the annual budget, with the PSP being the union's variable remuneration. Such statements are consistent with the management accounting literature (Groen et al., 2017; Ittner, Larcker, e Meyer, 2003), as objective performance indicators are guided according to the organization's budget.

It is noteworthy that the objective and the subjective performance evaluation occur through formal and informal controls that are the macro performance indicators in the case of objective evaluation. The union monitors this data using formal controls, such as the Business Intelligence (BI) system, considered a "Traffic Light," making it possible to verify the results' daily verification and, later, the formal meetings.

The BI system allows regional managers and service point coordinators to designate the evaluation of the performance indicators that have been designed to promote performance actions. According to Coordinator 2 , the evaluation of the indicators promotes internal action among employees. According to her example, "there is the indicator that I already reached, where do I need to spend more energy? What are we going to do differently? What are we going to do to stimulate it?" Thus, following up the indicator panel allows managers to assess the main growth numbers and the main credit portfolios, among other factors.

In addition to evaluating the performance indicators, information cascade meetings are held to create internal leverage actions for the objectives. According to Manager 1, "formal meetings take place once a month with the board, every fifteen days with managers, and once a month with coordinators." In addition to the objective performance evaluation based on indicators, the union conducts subjective evaluations, assessing competencies whose focus is to follow-up the employee's development in the union.

The competency assessment is annual and occurs jointly in the whole union during a specific period. In the subjective evaluation, employees are assessed through four competencies considered essential: interpersonal relationships, assertive communication, sense of cooperation, and focus on economic and social results. These four competencies are evaluated according to each function, distributed among directors, managers, coordinators, and analysts. Consequently, the union has so-called functional competencies, which are also divided according to each function but must be practiced every day.

The performance evaluation of the union's employees is part of the Individual Development Plan (PDI). According to the documents made available, this evaluation program occurs when the employee completes 12 months in the union; the focus of analysis is on individual evaluations between the leader and the led. According to Coordinator 4: "Its format is that the employee does the self-assessment, the leader does his selfassessment, and the evaluation's result is a consensus of these two." With all this individual analysis, the general objective is the development of all employees, with the union's support in the individual and, consequently, collective strengths and weaknesses.

Within the service stations, every three or four months, the coordinators provide formal feedbacks based on the action plans agreed in the annual evaluation, when they are filled out, talked about, and registered in the passport. Moreover, as informal feedbacks, there are daily conversations. According to Coordinator 1: "[...] through the informal follow-ups and the development plan of what you perceive in the performance evaluation needing improvement, some actions are launched for the employee." The follow-up of employees and the use of feedback for performance evaluation are considered fundamental mechanisms for long-term development, as Bol and Smith (2011) stated.

In this sense, actions for the development of the employee are able, in most cases, to generate learning effectively and efficiently. However, actions only generate results if they are monitored, as stated by Coordinator 1: "[...] you have to follow-up, you have to perceive. I am not going to say that there are cases that do not happen, 
not succeed, but then it is up to the coordinator to perceive the right person in the right place, and maybe he perceives that sign". Therefore, individual follow-up is one of the bases for developing this employee and, later, of the team. According to Coordinator 4, if there were no such moment of feedback that the subjective evaluation proposes, "[...], we would leave it very loose [...] So I think the loss would also be of clarity and the guarantee of a formal moment for that".

In general, considering the objective evaluation (the objective being the basis of the PSP), the union has concise performance assessments at the individual level to assess competencies and teams. The objective evaluation does not occur at the individual level but from a collective perspective. According to Coordinator 4, regarding the performance indicators that guide the PSP: "they are our performance indicators, but they are collective performance indicators, of the whole union, so the PSP is our result evaluation, it is objective."

Both evaluations (objective and subjective) are essential for the union; combining these two types of evaluation is effective for individual and joint development.

\section{INTERDEPENDENCE BETWEEN GAINSHARING AND PERFORMANCE EVALUATION}

The discussion proposed by Bedford (2020) allows deepening how interdependence (treated in terms of complementarity and substitution) and independence between management control practices are manifested in practice. Considering the investigation on the interdependence between management control practices, gainsharing, the objective, and subjective performance evaluation, we can proceed with some reflections.

First, concerning the interdependence between subjective assessment and objective performance evaluation, both are identified as focusing on aspects and hierarchical levels differently. Subjective performance evaluation occurs at the individual level and is based on attributes related to essential and functional competencies that have different views according to hierarchical levels (Beuren et al., 2020; Moers, 2005). Thus, the levels are characterized as behavioral evidence: directors, managers, and analysts; each has different responsibilities and needs to exercise specific behavior.

On the other hand, objective evaluation is the responsibility of performance indicators, based on the cooperative's strategic planning, involving organizational levels, globally, regionally, or service stations (Woods, 2012). In this context, objective evaluation relates to formal and informal channels that can verify and follow up the organization's results, aiming to direct efforts (Ittner, Larcker, \& Meyer, 2003; Moers, 2005). However, it is complex to capture the problems related to interpersonal skills and the need for each organizational level only through meetings, analysis of each indicator's results, or informal conversations (Bol \& Smith, 2011; Kunz, 2015).

Thus, the subjective evaluation is considered as focusing on the development of the employee to mitigate personal limitations that the objective evaluation cannot capture. The union analyzes its results, focusing on the group, in which achieving the objectives depends on the alignment of efforts and motivation. Therefore, the subjective evaluation helps with the control and behavioral analysis of each person through individual development plans, i.e., the control of the employee's commitment and performance becomes an essential factor so that he/she remains motivated and directed to achieve the organizational objectives.

Another critical factor to consider is that the development plan carried out with each individual can be changed at any time after providing feedback, and these follow-up factors can generate opportunities to improve organizational performance (Gibbs et al., 2004). In this sense, Coordinator 4 reports that: "As our teams are all in very similar positions, we can look at this and within the regional, for example, suggest some transfers to make the team more balanced, in a sense to give more impetus to the development of people."

Therefore, it is surprising how the performance evaluation focused on the employee's subjective indicators can act to compensate for the limitations of the objective performance evaluation, allowing to deal with problems of motivation and alignment of interests (Merchant \& Van der Stede, 2014). Thus, the feeling of working in a team and motivation (financial and non-financial) encourages employees to carry out their activities in line with strategic objectives and, at the same time, achieve their functional performance.

Finally, the complementary compensatory element proposed by Bedford (2020) and identified in the union deals with the evolution of the employee concerning the development of skills, for example, the positive results of individual action plans. As listed by Coordinator 4, the link between subjective evaluation and objective evaluation is the consequences of employee behavior, 
"[...] because the employee works more assertively, he is more connected with the union, so the more the employees evolve, the better it is to develop a result at work [...]" Although the objective assessment is not analyzed individually, its weaknesses can be mitigated by subjective evaluation, because, according to Coordinator 4 , "[...] the development of the employee, the evolution of the employee, will generate direct impact in the result of the union", by monitoring the results and implementing action plans. Thus, we arrive at Proposition 1 (P1): “The subjective performance evaluation neutralizes the weaknesses or limitations of the objective performance evaluation in solving the problem of controlling the limitation of competencies."

Second, regarding the interdependence between gainsharing and objective performance evaluation, it can be said that the first practice increases the effectiveness of the second in mitigating the problems of lack of direction and lack of motivation (Bedford, 2020) in the studied union. Friis et al. (2015) also support increasing the effectiveness of management control in the organization. Therefore, it is argued that the complementarity between these two practices can be qualified within the causal form called reinforcement by Bedford (2020).

As for the evidence from the field that suggests this relationship, it is clear that the performance indicators defined for gainsharing are used more intensively, both from a formal and an informal point of view, in the service stations' objective performance evaluation concerning the organization. As formal controls, the union monitors and evaluates the indicators in real-time through the BI system and, subsequently, holds formal meetings to discuss action plans. As for informal controls, they refer to communications through various mechanisms, with a certain level of autonomy, as reported by Manager 1: "it occurs by phone, message, e-mail or in person when I am going to do something very different, then I go there with the director and say what I was thinking."

Thus, the complementarity between the gainsharing and the objective performance evaluation is also evidenced by the fact that the gainsharing indicators result from the Strategic Planning indicators and, therefore, are the same indicators that guide the objective performance evaluation. It is worth mentioning that, for the design of gainsharing, performance indicators are defined. However, weights are assigned, and the characteristic goals that direct managers' attention in the process of objective performance evaluation are reviewed through formal channels (such as meetings, systems with real-time data) and informal (such as conversations or questioning by telephone, e-mails, face-to-face) (Hartman \& Slapničar, 2012).

In other words, gainsharing and objective performance evaluation are based mainly on the same performance indicators, which tend to increase the effectiveness of both management control practices, as well as assist in guiding and assisting the union's employees towards achieving superior results, from the administrative headquarters to the "lower-end," i.e., the service stations. On the other hand, informal face-to-face conversations tend to facilitate the creation of ideas to achieve the organization's objective (Van Veen-Dirks, 2010; Zondo, 2018). Figure 1 shows how gainsharing complements the objective performance evaluation, particularly by reinforcing its role of influencing behaviors and promoting the direction to achieve the objectives.
- Monitoring and follow-up of performance indicators:

○ BI: system that allows monitoring in real time.

○ Quick Meetings: weekly or, when necessary, involving the team itself.

o Meetings: monthly, involving the team itself.

o Follow-up meetings: monthly or, when necessary, involving the management and board members.
- PPR communication: "cascading" of information and how it is worked to be 'incorporated' in the teams.

- Follow-up discussions in the union as a whole to evaluate and improve the results:

- Regarding the performance of the indicators for the current semester.

- Regarding the definition of indicators and respective weights for the following semester.

- Regarding the process of improving the PPR practice.

Figure 1 Complementarity between gainsharing and objective performance evaluation Source: Prepared by the authors. 
Therefore, in the union, gainsharing acts as a practice capable of assisting in the efficacy of objective performance evaluation. In other words, it is a guideline through which indicators are observed, instigated, and changed every six months. Thus, according to Coordinator 4: "I believe that the PSP has an important recognition function, which makes people look for it, has an impact on the employee's eyes and this ends up motivating the search for results." In other words, gainsharing promotes debate by aligning efforts and, at the same time, motivates employees to achieve results. Based on the above, Proposition 2 (P2) is established: "Gainsharing increases the effectiveness of objective performance evaluation in mitigating problems related to lack of motivation and lack of direction."

Third, considering the relationship between gainsharing and subjective performance evaluation, it is clear that they are interdependent practices in which gainsharing is developed, by a group responsible in the union, based on objective performance indicators, which may vary according to the need for each semester, and subjective performance evaluation, focusing on the individual's skills. The indicators that are part of the gainsharing correspond to the union's results and its members, for example, fundraising, credit operations, linkage of cooperative members, default, number of members, and satisfaction survey.

On the other hand, subjective performance evaluation is directly linked to the employee's skills. Individual evaluations are carried out, as well as PDI insertion, in addition to frequent feedbacks to analyze the behavior of employees given their commitment to evolve. The use of this subjective evaluation aims to mitigate problems of personal and behavioral limitations. This development does not occur immediately but gradually, which can result in future rewards.

Therefore, the performance assessment focusing on the employee tends to influence the results of individual and collective behavior based on the change in the behavior of these employees. The long-term vision indirectly influences the resolution of personal problems, aiding to direct objectives promoted by the PSP. According to Manager 1: "regardless of the PSP, the evaluation of competencies generates better results, and we develop more mature, more confident teams."

Thus, the subjective performance evaluation can be considered as having an enabling effect on the gainsharing in the union if the employee develops his skills. For example, "focus on economic and social results," which means the ability to plan, decide, guide, and execute actions that benefit the results of the union and the community that, aligned with strategic planning, tend to generate performances that result in achieving PSP.

Also, the subjective indicators only concerning the employee's subjective evaluation act indirectly in the optimization of the PSP through the actions of the PDI of the individual performance evaluation. As indicated by Bol and Smith (2011), subjective performance evaluation tends to generate long-term benefits. Still, according to Kunz (2015), there is a change in people's behavior when managers complement the idea of objective and subjective performance evaluation, as the employee ends up adapting to the organizational culture and the managers manage to influence the change in the employees' behavior based on in other perspectives, aiming to improve motivation and, consequently, individual and organizational performance in the company. Then, Proposition 3 (P3) is presented: "By mitigating problems of personal limitations, subjective performance evaluation creates the conditions for gainsharing to contribute to the resolution of longterm motivation and management problems."

Given this discussion supported by Bedford's model (2020), three propositions were elaborated reflecting the complementarity between the practices studied (Figure 2).

\begin{tabular}{|c|c|c|}
\hline \multirow{2}{*}{$\begin{array}{c}\text { Subjective performance } \\
\text { evaluation }\end{array}$} & P1: Compensates & \multirow{2}{*}{$\begin{array}{c}\text { Objective performance } \\
\text { evaluation }\end{array}$} \\
\hline & \multirow[b]{2}{*}{ P2: Reinforces } & \\
\hline \multirow{2}{*}{$\begin{array}{l}\text { Reward system - } \\
\text { Gainsharing }\end{array}$} & & \multirow{2}{*}{$\begin{array}{c}\text { Objective performance } \\
\text { evaluation }\end{array}$} \\
\hline & \multirow[b]{2}{*}{ P3: Enables } & \\
\hline \multirow{2}{*}{$\begin{array}{c}\text { Subjective performance } \\
\text { evaluation }\end{array}$} & & \multirow{2}{*}{$\begin{array}{l}\text { Reward system - } \\
\text { Gainsharing }\end{array}$} \\
\hline & & \\
\hline
\end{tabular}

Figure 2 Theoretical research model Source: Prepared by the authors. 


\section{FINAL REMARKS}

This study investigates the interdependence between gainsharing and performance evaluation (objective and subjective) in a credit union. Therefore, interviews were conducted, and documents were analyzed to capture the structure of the union, the characteristics of gainsharing (PSP), the performance indicators used, and how objective and subjective performance evaluation occurs at the different hierarchical levels of the union - board, management, and coordination of service stations.

Thus, this study contributed to the management control literature by discussing interdependence and specifically analyzing the complementarity between management control practices, which is recent in the area (Bedford, 2020; Choi, 2020; Merchant \& Otley, 2020). It focused on gainsharing practices and objective and subjective performance evaluation, which are used intensively by the union and have been little explored jointly by previous studies. From a practical point of view, the context of credit unions has made it possible to analyze how gainsharing is positioned due to social and collective principles and the use of performance evaluation mechanisms concerning results control.

Subsequently, the interdependence between gainsharing and the objective and subjective performance assessment was identified as evidenced through three elements of complementarity - compensatory, reinforcing, and enabling - characterized by Bedford (2020). In this sense, the subjective performance evaluation is noted to seek to compensate for the weaknesses and limitations concerning objective performance evaluation skills. Therefore, gainsharing reinforces the objective performance evaluation process, increasing effectiveness by mitigating motivation and direction problems, while subjective performance evaluation enables gainsharing to act in the motivation and direction towards long-term objectives after mitigating competence limitations.

Despite the contributions, this study has some limitations. Among them, we highlight the selection of service stations and interviewees, which may highlight other realities in the organization not captured in this research. Furthermore, as it is a specific case study with a credit union, the results cannot be generalized.

As a suggestion for future research, analyzing multiple cases is recommended, such as investigating gainsharing or evaluating performance with other management control mechanisms, aiming levels of integration and degree of efficacy (Bedford, 2020; Demartini \& Otley, 2020). Also, qualitative studies are suggested to deepen the discussion of complementarity (integration and substitution) and its emphasis on organizational results (Merchant \& Otley, 2020). Finally, the development of studies is suggested, analyzing the complementarity between two or more systems from a longitudinal perspective and, even, on other sectors, as it is an area with little empirical evidence.

\section{REFERENCES}

Aguiar, A. B. D., Teixeira, A. J. C., Nossa, V., \& Gonzaga, R. P. (2012). Associação entre sistema de incentivos gerenciais e práticas de contabilidade gerencial. Revista de Administração de Empresas, 52(1), 40-54.

Ahrens, T., \& Chapman, C. S. (2006). Doing qualitative field research in management accounting: Positioning data to contribute to theory. In C. S. Chapman, A. G. Hopwood, \& M. D. Shields (Ed.), Handbooks of management accounting research (Vol. 1, pp. 299-318). Amsterdam, Holanda: Elsevier.

Arthur, J. B., \& Kim, D. O. (2005). Gainsharing and knowledge sharing: the effects of labour-management co-operation. The International Journal of Human Resource Management, 16(9), 1564-1582.

Bedford, D. S. (2020). Conceptual and empirical issues in understanding management control combinations. Accounting, Organizations and Society, 86, 101187.

Bedford, D. S., Malmi, T., \& Sandelin, M. (2016). Management control effectiveness and strategy: An empirical analysis of packages and systems. Accounting, Organizations and Society, $51,12-28$.

Beuren, I. M., Von Eggert, N. S., \& Santos, E. A. (2020). Influência da avaliação de desempenho formal e seus mecanismos na confiança interpessoal entre gestores: justiça processual e qualidade do feedback percebidos. Organizações \& Sociedade, 27(92), 113-131.

Bol, J. C. (2008). Subjectivity in compensation contracting. Journal of Accounting Literature, 27, 1-32.

Bol, J. C., \& Smith, S. D. (2011). Spillover effects in subjective performance evaluation: Bias and the asymmetric influence of controllability. The Accounting Review, 86(4), 1213-1230.

Bonner, S. E., \& Sprinkle, G. B. (2002). The effects of monetary incentives on effort and task performance: theories, evidence, and a framework for research. Accounting, Organizations and Society, 27(4-5), 303-345.

Brickley, J., Smith, C., \& Zimmerman, J. (2015). Managerial economics and organizational architecture. New York, NY: McGraw-Hill Education. 
Case, J. (1998). The open-book experience: Lessons from over 100 companies who successfully transformed themselves. Basic Books.

Chenhall, R. H., \& Langfield-Smith, K. (2003). Performance measurement and reward systems, trust, and strategic change. Journal of Management Accounting Research, 15(1), 117-143.

Choi, J. W. (2020). Studying "and": a perspective on studying the interdependence between management control practices. Accounting, Organizations and Society, 86, 101188.

Chua, W. F. (1986). Radical developments in accounting thought. Accounting Review, 61(4), 601-632.

Crotty, M. (1998). The foundations of social research: meaning and perspective in the research process. Thousand Oaks, CA: Sage.

Demartini, M. C., \& Otley, D. (2020). Beyond the system vs. package dualism in performance management systems design: a loose coupling approach. Accounting, Organizations and Society, 86, 101072.

Doucouliagos, H., Laroche, P., Kruse, D. L., \& Stanley, T. D. (2020). Is profit sharing productive? A meta-regression analysis. British Journal of Industrial Relations, 58(2), 364-395.

Dubois, A., \& Gadde, L. E. (2002). Systematic combining: an abductive approach to case research. Journal of Business Research, 55(7), 553-560.

Ferreira, A., \& Otley, D. (2009). The design and use of performance management systems: an extended framework for analysis. Management Accounting Research, 20(4), 263 282.

Frezatti, F. (2009). Orçamento empresarial: planejamento e controle gerencial. São Paulo, SP: Atlas.

Friis, I., Hansen, A., \& Vámosi, T. (2015). On the effectiveness of incentive pay: exploring complementarities and substitution between management control system elements in a manufacturing firm. European Accounting Review, 24(2), 241-276.

Gerhart, B., Rynes, S. L., \& Fulmer, I. S. (2009). 6 pay and performance: individuals, groups, and executives. Academy of Management Annals, 3(1), 251-315.

Gibbs, M., Merchant, K. A., Stede, W. A. V. D., \& Vargus, M. E. (2004). Determinants and effects of subjectivity in incentives. The Accounting Review, 79(2), 409-436.

Gomez-Mejia, L. R., Welbourne, T. M., \& Wiseman, R. M. (2000). The role of risk sharing and risk taking under gainsharing. Academy of Management Review, 25(3), 492-507.

Grabner, I., \& Moers, F. (2013). Management control as a system or a package? Conceptual and empirical issues. Accounting, Organizations and Society, 38(6-7), 407-419.

Grafton, J., Lillis, A. M., \& Widener, S. K. (2010). The role of performance measurement and evaluation in building organizational capabilities and performance. Accounting, Organizations and Society, 35(7), 689-706.

Groen, B. A., Wouters, M. J., \& Wilderom, C. P. M. (2017). Employee participation, performance metrics, and job performance: a survey study based on self-determination theory. Management Accounting Research, 36, 51-66.

Hartmann, F., \& Slapničar, S. (2012). The perceived fairness of performance evaluation: the role of uncertainty. Management Accounting Research, 23(1), 17-33.

He, W., Li, S. L., Feng, J., Zhang, G., \& StuHe, W., Li, S. L., Feng, J., Zhang, G., \& Sturman, M. C. (2020). When does pay for performance motivate employee helping behavior? The contextual influence of performance subjectivity. Academy of Management Journal, (in press).

Ittner, C. D., Larcker, D. F., \& Meyer, M. W. (2003). Subjectivity and the weighting of performance measures: Evidence from a balanced scorecard. The Accounting Review, 78(3), 725758.

Jordan, S., \& Messner, M. (2012). Enabling control and the problem of incomplete performance indicators. Accounting, Organizations and Society, 37(8), 544-564.

Jovanović, T., Arnold, C., \& Voigt, K. I. (2017). Cooperative banks in need of transition: the influence of Basel III on the business model of German cooperative credit institutions. Journal of Co-operative Organization and Management, 5(1), 39-47.

Kunz, J. (2015). Objectivity and subjectivity in performance evaluation and autonomous motivation: an exploratory study. Management Accounting Research, 27, 27-46.

Kgoedi, T., \& Pillay, A. S. (2018). The impact of compensation on the performance of employees at a bank in Mpumalanga. Journal of Management \& Administration, 2018(2), 135-162.

Lau, C. M., \& Moser, A. (2008). Behavioral effect of nonfinancial performance measures: the role of procedural fairness. Behavioral Research in Accounting, 20(1), 55-71.

Lukka, K. (2014). Exploring the possibilities for causal explanation in interpretive research. Accounting, Organizations and Society, 39(7), 559-566.

Malmi, T., \& Brown, D. A. (2008). Management control systems as a package: opportunities, challenges and research directions. Management Accounting Research, 19(4), 287-300.

Masternak, R. L., \& Ross, T. L. (1992). Gainsharing: a bonus plan or employee involvement? Compensation \& Benefits Review, 24(1), 46-54.

Merchant, K. A., \& Otley, D. (2020). Beyond the systems versus package debate. Accounting, Organizations and Society, 86, 101185.

Merchant, K. A., \& Van der Stede, W. A. (2014). Management control systems: performance measurement, evaluation and incentives. London, United Kingdom: Pearson Education.

Moers, F. (2005). Discretion and bias in performance evaluation: the impact of diversity and subjectivity. Accounting, Organizations and Society, 30(1), 67-80.

Nyberg, A. J., Maltarich, M. A., Abdulsalam, D. D., Essman, S. M., \& Cragun, O. (2018). Collective pay for performance: a cross-disciplinary review and meta-analysis. Journal of Management, 44(6), 2433-2472. 
Pizzini, M. (2010). Group-based compensation in professional service firms: an empirical analysis of medical group practices. The Accounting Review, 85(1), 343-380.

Timmermans, S., \& Tavory, I. (2012). Theory construction in qualitative research from grounded theory to abductive analysis. Sociological Theory, 30(3), 167-186.

Van Veen-Dirks, P. (2010). Different uses of performance measures: the evaluation versus reward of production managers. Accounting, Organizations and Society, 35(2), 141164.
Welbourne, T. M., \& Gomez-Mejia, L. R. 1995. Gainsharing: A critical review and a future research agenda. Journal of Management, 21(3), 559-609.

Woods, A. (2012). Subjective adjustments to objective performance measures: the influence of prior performance. Accounting, Organizations and Society, 37(6), 403-425.

Zondo, R. W. (2018). The impact of gainsharing in the automotive parts manufacturing industry of South Africa. South African Journal of Economic and Management Sciences, 21(1), 1-8. 